\title{
A Functional Role for the 'Fibroblast-Like Cells' in Gastrointestinal Smooth Muscles
} (J Physiol 2011;589[Pt 3]:697-710)

\author{
Hyun Jin Kim \\ Department of Internal Medicine and Institute of Health Science, Gyeongsang National University School of Medicine, Jinju, Gyeongsangnam-do, \\ Korea
}

\section{Summary}

The physiologic role of fibroblast-like cells (FLCs) has not been well established. Recently Kurahashi et al ${ }^{1}$ suggested the involvement of FLCs in neurotransmission by $\mathrm{Ca}^{2+}$-activated $\mathrm{K}^{+}$ (SK3) channels. They demonstrated that a network of more extensively branching cells with platelet-derived growth factor receptor alpha (PDGFR $\mathrm{P}_{\alpha}$ ) existed between the circular and longitudinal muscles in the plane of the myenteric plexus. FLCs $\left(\mathrm{PDGFR}_{\alpha}+\right)$ were located in the same anatomical spaces and distributed in similar density as interstitial cells of Cajal (ICC), but $\mathrm{PDGFR}_{\alpha}+$ cells were distinct from c-Kit + ICC, as shown by double labeling. Other double labeling experiments with anti-SK3 antibody revealed that $\mathrm{PDGFR}_{\alpha}+$ cells in both muscle layers and the region of the myenteric plexus expressed SK3. Some other experiments showed that $\mathrm{PDGFR}_{\alpha}+$ cells labeled with enhanced green fluorescent protein (eGFP) produced robust expression of P2ry1 (P2Y1 receptors) and Kcnn3 (SK3 channels).

Whole-cell patch clamp results suggested that $\mathrm{PDGFR}_{\alpha}+$ cells express a high density of apamin-sensitive $\mathrm{Ca}^{2+}$-activated $\mathrm{K}^{+}$channels, which is consistent with the expression of SK3 channels: small amplitude and time-dependent outward currents without voltage-dependent inward currents in step depolarization, and significant reduction of this currents by apamin $300 \mathrm{nM}$ and charybdotoxin (block both BK and IK conductance $\mathrm{Ca}^{2+}$ activated $\mathrm{K}^{+}$channels) caused a small but significant reduction in outward currents. Single channel patch recording (excised inside-out patch) to change $\mathrm{Ca}^{2+}$ at the intracellular surface produced the results consistent with previous reported data of $\mathrm{Ca}^{2+}$ activated $\mathrm{K}^{+}$channels. Pharmacological data using purines (ATP, $\beta$-NAD and ADP) evoked significant outward currents in PDGFR $\alpha+$ cells. Apamin and MRS2500 (P2Y1 antagonist) attenuated current amplitudes.

The authors concluded that $\mathrm{PDGFR}_{\alpha}+$ cells are a novel class of excitable cells with large current densities attributable to SK channels that are the molecular and ionic apparatus to mediate enteric inhibitory responses to purines in gastrointestinal (GI) muscles.

\section{Comment}

FLCs are one kind of interstitial cells in smooth muscles. The most famous interstitial cell is ICC, which serves as a pacemaker that creates the slow waves leading to peristaltic con-

Received: August 4, 2011 Revised: August 11, 2011 Accepted: August 13, 2011

(c) This is an Open Access article distributed under the terms of the Creative Commons Attribution Non-Commercial License (http://creativecommons. org/licenses/by-nc/3.0) which permits unrestricted non-commercial use, distribution, and reproduction in any medium, provided the original work is properly cited.

*Correspondence: Hyun Jin Kim, MD

Department of Internal Medicine, School of Medicine, Gyeongsang National University, 90 Chilam-dong, Jinju, Gyeongsangnam-do 660-702, Korea

Financial support: None.

Tel: +82-55-750-8285, Fax: +82-55-758-9122, E-mail: imdrkim@naver.com

Conflicts of interest: None. 
traction of the smooth muscles in the GI tract. ${ }^{1}$ FLCs belong to the same kinase group as c-Kit receptor tyrosine kinase that is specifically expressed in the ICC of GI tract. ${ }^{2}$

PDGFR is a type III receptor tyrosine kinase structurally similar to c-Kit and is expressed in many organs as well as in the GI tract. ${ }^{2}$ Thus FLCs can actually be labelled robustly with antibody of $\mathrm{PDGFR}_{\alpha}{ }^{3}$, as ICC labelled with antibody of c-Kit. Double labelling with $\mathrm{PDGFR}_{\alpha}+$ and c-Kit antibodies shows that FLCs and ICC are distinct populations and the distribution of PDGFR $\mathrm{PD}_{\alpha}+$ cells is unaffected in $W$ mutants (rodents to lack a specific type of ICC). ${ }^{2}$

Anatomically, FLCs were observed in the musculature in all parts of the GI tract. ${ }^{1,2}$ These cells were closely associated with intramuscular ICC and enteric nerve fibers. In immunohistochemical studies, FLCs are communicated with neuron and smooth muscle cells by gap junction ( $<20 \mathrm{~nm}$ length). ${ }^{4}$ In the myenteric layer, FLCs formed a cellular network with their ramified processes and encompassed myenteric ganglia. Numerous PDGFR ${ }_{\alpha}+$ cells observed in the subserosal plane showed a multipolar shape. ${ }^{4}$ The fact that $\mathrm{PDGFR}_{\alpha}+$ cells share similar anatomical distributions with ICC suggests that the nomenclature similar to that used for different classes of ICC would be useful in order to distinguish PDGFR $\alpha+$ cells (eg, PDGFR + - IM [intramuscular] and $\mathrm{PDGFR}_{\alpha}+-\mathrm{MY}$ [myenteric] $)^{2}$

Ultrastructurally, FLCs have cytoplasm of moderate to high electron density, well-developed rough endoplasmic reticulum, and nuclei with thick peripheral accumulation of heterochromatin. There were no basal lamina and caveolae along the cell membrane. It was also observed that single fibroblast-like cells formed probable small gap junctions with muscle cells. ${ }^{4}$

$\mathrm{PDGFR}_{\alpha}+-\mathrm{MY}$ expresses small-conductance $\mathrm{Ca}^{2+}$-activated $\mathrm{K}^{+}$channels, a potential mediator of purinergic enteric inhibition. ${ }^{4}$ And it is closely related with inhibitory (neural nitric oxide synthase + ) and excitatory (vesicular acetylcholine transporter $[\mathrm{vAchT}]+$ ) enteric motor neurons. ${ }^{1}$

The development of eGFP cells enabled some studies of specific cells (ie, immunoreactivity study, patch clamp etc). Realtime PCR for relative expression of Kit, P2ry1 and Kcnn3 resulted in robust expression of P2ry1 and Kcnn2 and very low expression of Kit, which meant that FLCs were a different kind of cells from ICC.

The results of patch clamp technique were as follows; (1) dialysis of cell with $\mathrm{Ca}^{2+}$-activated enormously small conductance $\mathrm{K}^{+}$currents which gene blocked by apamin; (2) application of ATP, ADP or $\beta$-NAD activated large amplitude; and (3) apamin-sensitive $\mathrm{K}^{+}$currents which was blocked by the P2Y1 antagonist (MRS2500). These results indicate that the whole responses are in such a close association with SK channels.

FLCs $\left(\mathrm{PDGFR}_{\alpha}+\right)$ have networks between enteric neurons and smooth muscle cells, and express many $\mathrm{Ca}^{2+}$-activated $\mathrm{K}^{+}$ channels in the muscle layers in the GI tract. And FLCs transduce the enteric inhibitory neural input from nerve terminals to smooth muscles as a primary mediator.

\section{References}

1. Kurahashi M, Zheng H, Dwyer L, Ward SM, Don Koh S, Sanders KM. A functional role for the 'fibroblast-like cells' in gastrointestinal smooth muscles. J Physiol 2011;589(Pt 3):697-710.

2. Iino S, Horiguchi K, Horiguchi S, Nojyo Y. c-Kit-negative fibroblast-like cells express platelet-derived growth factor receptor alpha in the murine gastrointestinal musculature. Histochem Cell Biol 2009;131:691-702.

3. Sanders KM, Hwang SJ, Ward SM. Neuroeffector apparatus in gastrointestinal smooth muscle organs. J Physiol 2010;588(Pt 23): 4621-4639.

4. Horiguchi K, Komuro T. Ultrastructural observations of fibroblast-like cells forming gap junctions in the $\mathrm{W} / \mathrm{W}(\mathrm{nu})$ mouse small intestine. J Auton Nerv Syst 2000;80:142-147. 